\title{
A Multivariate Investigation into Academic Procrastination of University Students
}

\author{
Sichan He \\ Graduate School of Education, University of Bristol, Bristol, UK \\ Email: sichan.he@outlook.com
}

How to cite this paper: He, S.C. (2017) A Multivariate Investigation into Academic Procrastination of University Students. Open Journal of Social Sciences, 5, 12-24. https://doi.org/10.4236/jss.2017.510002

Received: August 11, 2017 Accepted: October 10, 2017 Published: October 13, 2017

\begin{abstract}
The study assessed the academic procrastination among students in the university of Bristol. The study enrolled 201 students from different ages, educational levels and country background. The study explored the prevalence of academic procrastination, and the reasons that render procrastinatory behaviors of university students, and the psychological influence that caused by procrastination. Findings showed that $97 \%$ students are affected by different effect of procrastination, $48 \%$ students "very often" or "always" procrastinate. Laziness, lack of motivation, stress, too much time internet use and difficulty of task are major identified reasons for academic procrastination. More than $80 \%$ students suffer from anxiety when they procrastinate.
\end{abstract}

\section{Keywords}

Academic Procrastination, Procrastination, Psychology, Educational Psychology, Self-Regulation

\section{Introduction}

Procrastination is very popular among many people of us. Procrastinators are well aware of the tasks they need to do, but they failed to carry out or complete the task timely because of procrastinating behaviors. Procrastination is also a very prevalent phenomenon among university students [1] [2]. Academic Procrastination is conceptualized as to delay in starting or completing a due academic task. As early as 1979, Ellis and Knaus [3] addressed that approximately $80 \%-95 \%$ of college students suffer from academic procrastination.

Increasing studies are paying more attention on the reasons that cause academic procrastination. Based on the reasons provided by students and teachers, prior research identified various reasons that lead to procrastination among 
university students. When students have fear of failure, they tend to procrastinate in starting or finishing due tasks [4]. More problematic internet use of internet addiction renders procrastination in studies [5], lack of guidance, lack of motivation, irrational time management, laziness, family issues, social problems, influence from peers are identified as reasons of procrastinating behaviors [6] [7] Procrastination can result in detrimental effect on academic performance as well as individuals psychological states. Procrastinators may suffer from embarrassment, anxiety, insomnia and depression [8] [9] [10]. Despite numerous related researches in academic procrastination, no research was seen conducted among students across different countries, and from different educational levels. The study explored the prevalence of academic procrastination among both local and international students at University of Bristol, with a sample size of 201 students. The current study analyzed the reasons that render students to procrastinate, and determine their perception toward possible treatments to rectify academic procrastination.

The current study intends to determine and analyze the various associating factors related to procrastination amongst the students of University of Bristol. The study is carried over a period of 3 months and collected data related to Undergraduate, Postgraduate (Masters) and Postgraduate Research (PhD) students.

The three main objectives of the research are: Prevalence of academic procrastination among students of University of Bristol; Comparison and identification of reasons for academic procrastination between undergraduates, postgraduates (Masters) and postgraduate research $(\mathrm{PhD})$ students using Academic Procrastination Scale (APS). In addition, comparison is done over the factors such as age, gender and local/international students. Determine the after effects (anxiety and eating habits) of academic procrastination and the perception of the students towards possible treatments (psychological and medicinal) of academic procrastination.

The remaining paper is organized in four sections. Section 2 titled Research Methodology discusses the methodology used for the data collection and the measurements. Section 3 is Data Analysis, which discusses the various issues pertinent to procrastination including the reasons and the after effects such as anxiety and stress. Section 4 provides the conclusion of the study. Section 5 and Section 6 describes the limitation and the future work for the study.

\section{Research Methodology}

The study conducted in this research is descriptive, which required an extensive survey to collect data from university students. The study was reviewed and approved by the ethical committee of Graduate School of Education of the University of Bristol and the research was conducted under their regulations. All the personal information such as student IDs, student emails were destroyed after ensuring the authenticity of the collected data. 


\subsection{Population and Sampling}

The study is limited to University of Bristol, United Kingdom. The population of the respondents are from three categories of students: Undergraduate, Postgraduate taught (Masters) and Postgraduate research $(\mathrm{PhD})$, which were chosen through random sampling technique. The sample of the study consists of 201 students, from different full-time courses.

\subsection{Data Collection}

A single questionnaire contains a Academic Procrastination Scale (APS) developed by Mccluskey [11], which is a 25-item, five-point Likert scale. The questionnaire was tested through pilot testing and reliability tests were also conducted. The final questionnaire was administered through Google sheets and shared on popular social media platforms frequented by the students of University of Bristol. The data was coded and analyzed with the help of APS (Academic Procrastination Scale) scores, means, correlation coefficients, percentages and regression analysis.

\section{Data Analysis}

The data collected through questionnaires is analyzed and presented to address the following issues, which includes gender, age, level of education, anxiety, time spent on social media, reasons for procrastination, change in food habits, level of self-realization of procrastination and perception towards possible remedies.

\subsection{Gender}

The total sample size of 201 students can be categorized into two gender groups: Male and Female. The number of male and female students is 62 and 139 respectively. The APS scores which are the dependent variable for both the independent groups (male and female), are normally distributed. There are no significant outliers for any of the group. Research such as Else-Quest et al. [12] had different conclusions when it comes to procrastination and influence of gender on it. Majority of researchers concluded that procrastination is weakly associated with males. However, in the current study although the mean of the overall APS score for men (69.92) is slightly higher than that of females (69.19) but further analysis with the help of independent samples $t$-test $(t(199)=0.282$ with $p=$ 0.787 , which is greater than 0.05 ) showed that there is no statistically significant difference of APS scores between the two genders. Therefore, it cannot be concluded that gender of university student influences their level of procrastination in academic and other day to day activities.

\subsection{Age}

The variation of age with academic procrastination is shown in Table 1. It is observed that the mean APS score is highest for the age group less than 20 and second highest for the age group $21-25$. 
Table 1. Mean APS scores for different age groups.

\begin{tabular}{cc}
\hline Age Range & Mean APS Scores \\
\hline$<20$ & 70 \\
$21-25$ & 69 \\
$26-30$ & 60 \\
$31-35$ & 67 \\
$36-40$ & 61 \\
$41-45$ & 62 \\
$>46$ & 62 \\
\hline
\end{tabular}

Svartdal et al. [13] and Steel \& Ferrari [14] observed that as age increases, the level of procrastination decreases. Similar, results were observed in the current study as well, which showed that age and overall APS scores are negatively correlated to each other, which implies that as age increases procrastination decreases. Both Kendall's Tau and Spearman's correlation coefficient is observed to be -0.1 and -0.1 , respectively. These results are statistically significant as the 2 -tailed significance ( $p=0.04 \& 0.04$ respectively) is lower than 0.05 . This is very much in conformity with previous studies.

\subsection{Level of Education}

There are three educational levels of participants this study: Undergraduates (n $=44)$, postgraduate taught $(\mathrm{n}=87)$ and postgraduate research students $(\mathrm{n}=70)$. The overall mean APS scores are 75.64, 61.84 and 65.44, respectively. These scores follow normal distribution and no outliers were detected in any of three categories. The correlation between the level of education and APS scores was determined with the help of Kendall's Tau $(-0.11)$ and Spearman's correlation coefficient $(-0.15)$. After establishing that continued education results in reduction of academic procrastination as the data shows statistically significant negative correlation, it is imperative to show that the three categories of students are statically different when compared in terms of their overall APS scores. This is done by using independent samples t-test, which shows that overall APS scores for Postgraduate masters and research students are not very different. However, the APS scores for undergraduate students are very different from both the categories. Therefore, it can be concluded that although academic procrastination decreases as a student progresses from undergraduate to postgraduate taught and then to research student, the level of procrastination amongst masters and research students is not very different from each other.

\subsection{Influence of Social Media}

It is observed that the number of hours spent on social media is positively correlated with academic procrastination scores. In other words, the respondents who spent more time on social media also showed higher levels of academic procras- 
tination. The analysis was done with the help of Kendall's Tau and Spearman's correlation coefficient, both of which were observed to be statistically significant at 0.24 and 0.31 , respectively. The results are very much similar to the research conducted by Masur et al. [15], Xu, Wang, \& David [16], which showed that distractions like social media (Facebook, etc.) create challenges to self-control, students who use Facebook frequently tend to procrastinate more than non-habitual Facebook using students[17]. Time spent on social media significantly impacts students' academic performance and even their overall well-being.

\subsection{Anxiety \& Stress and Its Effect of Dietary Habits}

Out of the 201 respondents, more than $80 \%$ of the respondents claim to suffer from anxiety and stress. Table 2 lists the frequency of anxiety and stress amongst the three student categories.

The level of anxiety is highest for postgraduate taught students. This can be attributed to the fact that most of the respondents in this category were international students who have come to UK to study for a course with duration of one year only. Compared to this undergraduate and $\mathrm{PhD}$ students have a more relaxed working environment. The anxiety and stress issues can result in significant change in the dietary habits as well. Approximately $40 \%$ of the respondents agreed that they tend to eat and drink more because of anxiety and stress related to procrastination. This is in accordance with the study result of Lay et al. [18], which showed procrastination has positive correlation with anxiety as well as stress, in addition, procrastination changes dilatory behavior.

Stress, anxiety and change in eating habits are the negative outcomes of academic procrastination. Previous studies also showed similar results. Solomon \& Rothblum [4] concluded from their research that academic procrastination causes poor performance, withdrawing from schools, low self-esteem, and increased levels of stress, anxiety and illness. Tice and Baumeister [19] showed in their research that the procrastinating students are healthier and without much stress at semesters beginning than students who don't procrastinate, but the former are more subjective to illness, getting lower marks toward the end of semesters, possibly because at semester end, preparation for exams are needed and deadlines of assignments are approaching.

\subsection{Satisfaction with University and Course Structure}

The respondents were asked whether university of Bristol was their first choice. Out of 201 respondents, 161 mentioned that it was indeed their first choice. The

Table 2. Presence of anxiety and stress (\%) amongst university students.

\begin{tabular}{cccc}
\hline Issues & Undergraduate & Postgraduate Taught (Masters) & Postgraduate Research (PhD) \\
\hline Anxiety & 84 & 90 & 86 \\
Stress & 41 & 46 & 48 \\
\hline
\end{tabular}


overall mean of the APS scores for those who answered in yes and no was 66.04 and 66.43 respectively. The APS scores for both the groups follow normal distribution and there are no outliers. However, as per independent samples $t$-test $(t(199)=-0.123$ for $p=0.902$, which is greater than 0.05$)$, there is no statistically significant difference between the two means. Therefore, it cannot be concluded that choice of university has a significant effect on the level of procrastination. Interestingly, when the same students were asked about the satisfaction with their course content, it was observed that the level of satisfaction of course has statistically significant negative correlation with the overall APS scores. The study used Kendall's tau and Spearman's correlation coefficient and calculated correlation coefficients as -0.138 and -0.179 , respectively. This study shows that the major effect on academic procrastination is not the choice of university but the course content of the taught or research degrees and the satisfaction with the teaching methods. Therefore, education psychologists and career counselors may guide the students to a course most suited for them. This should help in the reduction of academic procrastination.

\subsection{Reasons for Procrastination amongst University Students}

The opinion of the students regarding the major reasons for academic procrastination was collected through the survey and presented here. All the identified variables in this section are observed to follow normal distribution. Separate reliability analysis was done for the variables used in this section and the Cronbach's alpha was computed to be 0.81 . A total of 201 responses were collected for each of the reasons given in Table below. This section identifies the reasons that lead to procrastination amongst undergraduate, postgraduate taught and postgraduate research students of University of Bristol. A detailed analysis is then carried out to determine the factors that affect procrastination. The major factors and their correlation with overall APS scores are listed in Table 3.

It is observed from the table that all the three categories of university students, identified certain common reasons for procrastination and there also few reasons, which are very specific to a certain category of students. For example, $31 \%$ postgraduate taught (Masters) and research $(\mathrm{PhD})$ students identified social problems as a reason for their academic procrastination while $36 \%$ undergraduate students disagreed with this reason. Inability to study is identified by $41 \%$ undergraduate students as the reason for procrastination while $37 \%$ postgraduate taught and $36 \%$ postgraduate research students disagreed with this reason. The same scenario is observed for lack of interest as a reason. 39\% undergraduate students disagreed while $29 \%$ and $37 \%$ postgraduate taught and research students, respectively agreed with it. Quite interestingly, almost 28\% postgraduate research students identified confusion about values and goals as their reason, to which $34 \%$ undergraduate and $28 \%$ postgraduate taught students disagreed. Postgraduate taught and research students identified difficult in setting tasks as one of the reasons for procrastination. 
Table 3. Reasons of procrastination amongst university students.

\begin{tabular}{|c|c|c|c|c|c|c|c|}
\hline \multirow{2}{*}{ Reasons } & \multirow{2}{*}{ Respondents } & \multicolumn{5}{|c|}{ Level of Agreement (\%) } & \multirow{2}{*}{$\begin{array}{l}\text { Mean } \\
\text { Score }\end{array}$} \\
\hline & & SDA & DA & UD & A & SA & \\
\hline \multirow{3}{*}{$\begin{array}{c}\text { Difficult } \\
\text { Course/Assignment }\end{array}$} & Undergraduate & 9.1 & 13.6 & 13.6 & 45.5 & 18.2 & 3.50 \\
\hline & Masters & 11.5 & 21.8 & 20.7 & 39.1 & 6.9 & 3.10 \\
\hline & $\mathrm{PhD}$ & 11.5 & 27.6 & 13.8 & 39.1 & 8.0 & 3.05 \\
\hline \multirow{3}{*}{ Fear of Failure } & Undergraduate & 11.4 & 27.3 & 18.2 & 25.0 & 18.2 & 3.11 \\
\hline & Masters & 19.5 & 28.7 & 10.3 & 26.4 & 14.9 & 2.89 \\
\hline & $\mathrm{PhD}$ & 14.9 & 36.8 & 10.3 & 19.5 & 18.4 & 2.90 \\
\hline \multirow{3}{*}{ Illness } & Undergraduate & 9.1 & 34.1 & 13.6 & 27.3 & 15.9 & 3.07 \\
\hline & Masters & 16.1 & 23.0 & 20.7 & 36.8 & 3.4 & 2.89 \\
\hline & $\mathrm{PhD}$ & 18.4 & 20.7 & 17.2 & 37.9 & 5.7 & 2.92 \\
\hline \multirow{3}{*}{ Social Problems } & Undergraduate & 13.6 & 36.4 & 13.6 & 29.5 & 6.8 & 2.79 \\
\hline & Masters & 16.1 & 28.7 & 16.1 & 31.0 & 8.0 & 2.86 \\
\hline & $\mathrm{PhD}$ & 14.9 & 29.9 & 16.1 & 32.2 & 6.9 & 2.86 \\
\hline \multirow{3}{*}{ Lack of Motivation } & Undergraduate & 0.0 & 9.1 & 2.3 & 50.0 & 38.6 & 4.18 \\
\hline & Masters & 6.9 & 16.1 & 11.5 & 46.0 & 19.5 & 3.55 \\
\hline & $\mathrm{PhD}$ & 2.3 & 5.7 & 11.5 & 44.8 & 35.6 & 4.06 \\
\hline \multirow{3}{*}{ Inability to Study } & Undergraduate & 6.8 & 29.5 & 9.1 & 40.9 & 13.6 & 3.25 \\
\hline & Masters & 13.8 & 36.8 & 21.8 & 23.0 & 4.6 & 2.68 \\
\hline & $\mathrm{PhD}$ & 9.2 & 35.6 & 17.2 & 27.6 & 10.3 & 2.94 \\
\hline \multirow{3}{*}{ Laziness } & Undergraduate & 11.4 & 15.9 & 4.5 & 36.4 & 31.8 & 3.61 \\
\hline & Masters & 10.3 & 11.5 & 9.2 & 42.5 & 26.4 & 3.63 \\
\hline & $\mathrm{PhD}$ & 5.7 & 9.2 & 13.8 & 39.1 & 32.2 & 3.83 \\
\hline \multirow{3}{*}{ Over-Confidence } & Undergraduate & 43.2 & 25.0 & 9.1 & 15.9 & 6.8 & 2.18 \\
\hline & Masters & 23.0 & 33.3 & 19.5 & 21.8 & 2.3 & 2.47 \\
\hline & $\mathrm{PhD}$ & 23.0 & 33.3 & 17.2 & 19.5 & 6.9 & 2.54 \\
\hline \multirow{3}{*}{$\begin{array}{c}\text { Teacher's } \\
\text { Attitude \& Feedback }\end{array}$} & Undergraduate & 11.4 & 22.7 & 29.5 & 25.0 & 11.4 & 3.02 \\
\hline & Masters & 11.5 & 28.7 & 28.7 & 25.3 & 5.7 & 2.85 \\
\hline & $\mathrm{PhD}$ & 11.5 & 32.2 & 28.7 & 21.8 & 5.7 & 2.78 \\
\hline \multirow{3}{*}{ Lack of Guidance } & Undergraduate & 11.4 & 20.5 & 11.4 & 38.6 & 18.2 & 3.32 \\
\hline & Masters & 6.9 & 23.0 & 20.7 & 39.1 & 10.3 & 3.23 \\
\hline & $\mathrm{PhD}$ & 9.2 & 18.4 & 19.5 & 39.1 & 13.8 & 3.30 \\
\hline \multirow{3}{*}{$\begin{array}{c}\text { Too Much } \\
\text { Course Work/Study }\end{array}$} & Undergraduate & 2.3 & 20.5 & 20.5 & 40.9 & 15.9 & 3.48 \\
\hline & Masters & 8.0 & 29.9 & 10.3 & 40.2 & 11.5 & 3.17 \\
\hline & $\mathrm{PhD}$ & 3.4 & 26.4 & 13.8 & 41.4 & 14.9 & 3.38 \\
\hline \multirow{3}{*}{ Stress } & Undergraduate & 6.8 & 11.4 & 11.4 & 45.5 & 25.0 & 3.70 \\
\hline & Masters & 4.6 & 13.8 & 9.2 & 48.3 & 24.1 & 3.74 \\
\hline & $\mathrm{PhD}$ & 5.7 & 13.8 & 5.7 & 40.2 & 34.5 & 3.84 \\
\hline
\end{tabular}




\section{Continued}

\begin{tabular}{|c|c|c|c|c|c|c|c|}
\hline \multirow{3}{*}{$\begin{array}{c}\text { Too Much Time } \\
\text { on Internet (Social Media) }\end{array}$} & Undergraduate & 6.8 & 11.4 & 9.1 & 36.4 & 36.4 & 3.84 \\
\hline & Masters & 6.9 & 18.4 & 10.3 & 39.1 & 25.3 & 3.57 \\
\hline & $\mathrm{PhD}$ & 2.3 & 10.3 & 12.6 & 41.4 & 33.3 & 3.94 \\
\hline \multirow{3}{*}{ Lack of Self Discipline } & Undergraduate & 6.8 & 9.1 & 13.6 & 34.1 & 36.4 & 3.84 \\
\hline & Masters & 3.4 & 12.6 & 12.6 & 46.0 & 25.3 & 3.77 \\
\hline & $\mathrm{PhD}$ & 3.4 & 6.9 & 12.6 & 41.4 & 35.6 & 3.99 \\
\hline \multirow{3}{*}{$\begin{array}{c}\text { Negative } \\
\text { Influence of Peers }\end{array}$} & Undergraduate & 18.2 & 43.2 & 18.2 & 15.9 & 4.5 & 2.45 \\
\hline & Masters & 20.7 & 40.2 & 19.5 & 16.1 & 3.4 & 2.41 \\
\hline & $\mathrm{PhD}$ & 19.5 & 33.3 & 14.9 & 27.6 & 4.6 & 2.64 \\
\hline \multirow{3}{*}{ Absence of Role Models } & Undergraduate & 40.9 & 34.6 & 9.1 & 11.4 & 0 & 1.91 \\
\hline & Masters & 29.9 & 40.2 & 14.9 & 13.8 & 1.1 & 2.16 \\
\hline & $\mathrm{PhD}$ & 32.2 & 35.6 & 11.5 & 12.6 & 8.0 & 2.29 \\
\hline \multirow{3}{*}{ Impatience } & Undergraduate & 11.4 & 25.0 & 15.9 & 40.9 & 6.8 & 3.07 \\
\hline & Masters & 9.2 & 27.6 & 24.1 & 28.6 & 10.3 & 3.03 \\
\hline & $\mathrm{PhD}$ & 8.0 & 26.4 & 21.8 & 26.4 & 17.2 & 3.18 \\
\hline \multirow{3}{*}{ Lack of Interest } & Undergraduate & 9.1 & 38.6 & 11.1 & 27.3 & 13.6 & 2.98 \\
\hline & Masters & 16.1 & 25.3 & 14.9 & 28.7 & 14.9 & 3.01 \\
\hline & $\mathrm{PhD}$ & 8.0 & 23.0 & 13.8 & 36.8 & 18.4 & 3.34 \\
\hline \multirow{3}{*}{$\begin{array}{l}\text { Confusion About } \\
\text { Values \& Goals }\end{array}$} & Undergraduate & 18.2 & 34.1 & 25.0 & 13.6 & 9.1 & 2.61 \\
\hline & Masters & 10.3 & 27.6 & 26.4 & 25.3 & 10.3 & 2.98 \\
\hline & $\mathrm{PhD}$ & 11.5 & 25.3 & 24.1 & 27.6 & 11.5 & 3.02 \\
\hline \multirow{3}{*}{$\begin{array}{c}\text { Difficult in } \\
\text { Setting Tasks }\end{array}$} & Undergraduate & 20.5 & 29.5 & 13.6 & 22.7 & 13.6 & 2.79 \\
\hline & Masters & 17.2 & 23.0 & 18.4 & 33.3 & 8.0 & 2.92 \\
\hline & $\mathrm{PhD}$ & 11.5 & 13.8 & 12.6 & 40.2 & 21.8 & 3.47 \\
\hline \multirow{3}{*}{ Language Barriers } & Undergraduate & 54.5 & 31.8 & 4.5 & 6.8 & 2.3 & 1.70 \\
\hline & Masters & 46.0 & 14.9 & 11.5 & 19.5 & 8.0 & 2.29 \\
\hline & $\mathrm{PhD}$ & 42.5 & 19.5 & 12.6 & 16.1 & 9.2 & 2.30 \\
\hline
\end{tabular}

To identify the major perceived reasons regarding procrastination, a further in-depth analysis through a regression model is developed. It helps to determine the major predictors/influencers for different categories of students. In this method association is determined between different reasons for procrastination and the APS score and to identify those factors, which account for the major variance in APS score. The reasons are listed in Table 4. The identified variables must be statistically significant with $p<0.05$.

\subsection{Level of Self-Realization of Procrastination and Perception towards Possible Remedies}

Out of the 201 students surveyed, almost $66 \%$ self-reported themselves as procrastinators. Table 5 lists the varying levels of this realization. 
Table 4. Major reasons identified for procrastination.

\begin{tabular}{|c|c|c|c|}
\hline $\begin{array}{l}\text { Student } \\
\text { Category }\end{array}$ & Reasons for Academic Procrastination & $\begin{array}{l}\text { Predictor } \\
\text { Importance }\end{array}$ & $\begin{array}{c}\text { Total } \\
\text { Variance }\end{array}$ \\
\hline \multirow{4}{*}{ Undergraduate } & Laziness & 0.33 & \multirow{4}{*}{$60.5 \%$} \\
\hline & Lack of Interest & 0.33 & \\
\hline & Lack of Self Discipline & 0.25 & \\
\hline & Impatience & 0.09 & \\
\hline \multirow{9}{*}{$\begin{array}{l}\text { Postgraduate } \\
\text { Taught } \\
\text { (Masters) }\end{array}$} & Lack of Self Discipline & 0.23 & \multirow{9}{*}{$44.9 \%$} \\
\hline & Difficult Course/Assignment & 0.17 & \\
\hline & Language Barrier & 0.14 & \\
\hline & Overconfidence & 0.10 & \\
\hline & Laziness & 0.09 & \\
\hline & Illness & 0.08 & \\
\hline & Confusion about values \& goals & 0.07 & \\
\hline & Lack of guidance & 0.06 & \\
\hline & Negative influence of peers & 0.06 & \\
\hline \multirow{8}{*}{$\begin{array}{c}\text { Postgraduate } \\
\text { Research } \\
(\mathrm{PhD})\end{array}$} & Laziness & 0.21 & \multirow{8}{*}{$53 \%$} \\
\hline & Illness & 0.21 & \\
\hline & Negative influence of peers & 0.21 & \\
\hline & Difficult Course/Assignment & 0.12 & \\
\hline & Absence of Role Models & 0.07 & \\
\hline & Teacher's attitude $\&$ feedback & 0.06 & \\
\hline & Impatience & 0.06 & \\
\hline & Inability to study & 0.05 & \\
\hline
\end{tabular}

Table 5. Level of self-realization of procrastination (\%).

\begin{tabular}{cc}
\hline Always & 12 \\
\hline Very Often & 36 \\
Sometimes & 37 \\
Rarely & 12 \\
Never & 3 \\
\hline
\end{tabular}

Approximately $85 \%$ of the respondents accepted that they suffer from varying levels of academic procrastination (from sometimes to always). The results are in conformity with the mean overall APS scores for the groups identified above and the same is listed in Table 6 below. Those with highest level of self-realization of academic procrastination also has the highest APS scores (90) and the students with lowest APS score (36), have the least self-perceived academic procrastination.

Table 6 shows level of self-reported academic procrastination is directly correlated with the mean APS scores. The study therefore concludes that the stu- 
Table 6. Level of self-realization and means APS scores.

\begin{tabular}{cc}
\hline Level of Academic Procrastination & Means APS Score \\
\hline Always & 89.88 \\
Very Often & 73.56 \\
Sometimes & 58.01 \\
Rarely & 50.30 \\
Never & 36.00 \\
\hline
\end{tabular}

Table 7. Level of self-realization and means APS scores for different categories of students.

\begin{tabular}{ccccccc}
\hline \multirow{2}{*}{$\begin{array}{c}\text { Level of } \\
\text { Self-Realization }\end{array}$} & \multicolumn{2}{c}{ Undergraduate } & $\begin{array}{c}\text { Postgraduate Taught } \\
\text { (Masters) }\end{array}$ & \multicolumn{2}{c}{$\begin{array}{c}\text { Postgraduate Research } \\
(\mathrm{PhD})\end{array}$} \\
\cline { 2 - 6 } & Mean & Frequency & Mean & Frequency & Mean & Frequency \\
\hline Always & 95.27 & 25.0 & 82.88 & 9.2 & 89.33 & 8.6 \\
Very Often & 80.00 & 34.1 & 72.23 & 29.9 & 71.55 & 44.3 \\
Sometimes & 63.85 & 29.5 & 56.62 & 42.5 & 57.08 & 37.1 \\
Rarely & 54.75 & 9.1 & 49.15 & 14.9 & 49.83 & 8.6 \\
Never & 31.00 & 2.3 & 35.00 & 3.4 & 44.00 & 1.4 \\
\hline
\end{tabular}

dents can judge their level of academic procrastination, which also agrees with their calculated mean APS scores based on the APS questionnaire. The next stage is to analyze the level of self-realization of Academic Procrastination among different categories of students at University of Bristol (Table 7).

Postgraduate research students, "very often" suffer from procrastination with the frequency higher than that of undergraduate students in the same band. Further, amongst all the student categories, only undergraduate students have the highest frequency of self-realization in the "always" category. These results are in conformity with the effect of age where it was observed that as age increase, the level of academic procrastination decreases.

\section{Conclusions}

Prevalence academic procrastination: The study used APS to analyze the prevalence of academic procrastination over parameters such as age, gender, education level, nationality, time spent on social media and the satisfaction with the university and course structure. The average of the overall APS scores for all the students is 66.11 and the median is 66.00 . The standard deviation is observed to be 17.78 .

The mean of the overall APS score for female students is 69.19, which is slightly lower than of male students. However, there is no statistically significant difference between the two. Therefore, gender cannot be considered as an influencing factor on academic procrastination. Therefore, the male and female students are almost equally affected by it. Age is negatively correlated (-0.109) 
with academic procrastination for the students at University of Bristol. As age increases, the academic procrastination decreases. The study also concluded that there is a statistically significant negative correlation $(-0.114)$ between the education and the level of academic procrastination. As a student progresses from undergraduate to $\mathrm{PhD}$, he/she procrastinates less for tasks related to academics. However, the correlation is not very strong and was observed to be -0.114 by Kendall's Tau. The study also observed that master students have the lowest value of overall APS score (61.84) in comparison to Undergraduates (75.64) and $\mathrm{PhD}$ (65.44). The study observed that there is no statistically significant difference between the means of overall APS scores between local and international students. The international students despite language and cultural barriers were observed to have an average overall APS score as 66.94 slightly higher than that of local students (64.61).

The study observed that as the amount of time spent on internet, mainly on social media increases, the level of academic procrastination increases too. All the categories of students at University of Bristol identified this as one of the major reasons for academic procrastination. Overall APS score for both international (58.52) and local students (55.40) is lowest for those who spend less than 1 hour on social media. It became imperative for the study to determine if there is any relationship between the level of satisfaction with the university and the course structure and academic procrastination. As the level of satisfaction with the course increases, the level of academic procrastination decreases.

The study also concluded that the APS scores for master's students, whether international (62.93) or local (59.27) have lower APS scores than undergraduate and PhD students. Females have lower APS scores for both international (66.81) and local students (64.22), although the mean APS scores are quite similar for international male (67.22) and female students (66.81). APS score for international students is lowest for age group $41-45$ (52.50), while for local students it is lowest for the age group 36 - 40 (49.00).

Reasons of academic procrastination: The study identified reasons for academic procrastination based on regression analysis. For undergraduate students, laziness, lack of interest, lack of self-discipline and impatience in decreasing order are the main reasons for academic procrastination. For master students, lack of self-discipline, difficult course/assignment, language barriers, overconfidence, laziness, illness, confusion above values and goals, lack of guidance and negative influence of peers in decreasing order are the main reasons for academic procrastination. Finally, for $\mathrm{PhD}$ students, the identified reasons are laziness, illness, negative influence of peers, difficult course/assignment, absence of role models, teacher's attitude and feedback, impatience and inability to study in decreasing order.

The self-realization amongst the students at University of Bristol that they procrastinate is quite high. Almost $86 \%$ of the surveyed students accepted that they procrastinate. Further, $12 \%$ and $36 \%$ stated that they procrastinate always or very often respectively. The study also concluded that Undergraduate stu- 
dents (34\%) feel that "very often" they suffer from academic procrastination. Further, $43 \%$ of master students feel that "sometimes" they suffer from academic procrastination. $44 \% \mathrm{PhD}$ students feel that "very often" they suffer from academic procrastination.

The study showed that $84 \%$ Undergraduates, $90 \%$ Masters and $86 \% \mathrm{PhD}$ students feel anxious or disturbed once they procrastinate on their academic tasks. Further, $41 \%$ undergraduates, $46 \%$ postgraduates and $48 \% \mathrm{PhD}$ students listed considered stress as the reason for their academic procrastination. These reasons can lead to serious psychological issues for the students and can further increase their level of academic procrastination. The study also showed that $68 \%$ Undergraduates, $68 \%$ Masters and $73 \% \mathrm{PhD}$ students tend to eat and drink more when they procrastinate.

\section{Limitations}

There are few limitations of the study, which are listed in this section. Prevalence was assessed via academic procrastination scale, which is based on self-perception of participants. The study was not able to include interviews and students' academic performance and study results, which might make the conclusions more objective and comparable. The sample size for few of the variables is limited. Study was conducted during summer vacation, many students left university, hence the number of participants less than expected.

\section{Future Work}

As per the results, some interventions and strategies may be applied to alleviate academic procrastination. For example, the difficulty of task can be flexible to ensure active participation of all students; counseling can be used for procrastinating students who suffer from fear of failure, problematic internet use, or social problems. Interest groups and incentive plans may help students who lack interest or motives in academic tasks. Student should improve self-control to lessen distraction that makes them procrastinate.

\section{Acknowledgements}

I would like to express my sincere gratitude to Dr. Sara Meadows, Graduate School of Education, University of Bristol, UK, under whose supervision this research was undertaken.

\section{References}

[1] Schraw, G., Wadkins, T. and Olafson, L. (2007) Doing the Things We Do: A Grounded Theory of Academic Procrastination. Journal of Educational Psychology, 99, 12. https://doi.org/10.1037/0022-0663.99.1.12

[2] Kandemir, M. (2014) Reasons of Academic Procrastination: Self-Regulation, Academic Self-Efficacy, Life Satisfaction and Demographics Variables. Procedia-Social and Behavioral Sciences, 152, 188-193. https://doi.org/10.1016/j.sbspro.2014.09.179

[3] Ellis, A. and Knaus, W.J. (1979) Overcoming Procrastination: Or, How to Think 
and Act Rationally in Spite of Life's Inevitable Hassles. Signet.

[4] Solomon, L.J. and Rothblum, E.D. (1984) Academic Procrastination: Frequency and Cognitive-Behavioral Correlates. Journal of Counseling Psychology, 31, 503-509. https://doi.org/10.1037/0022-0167.31.4.503

[5] Nalwa, K. and Anand, A.P. (2003) Internet Addiction in Students: A Cause of Concern. CyberPsychology \& Behavior, 6, 653-656. https://doi.org/10.1089/109493103322725441

[6] Díaz-Morales, J.F., Ferrari, J.R. and Cohen, J.R. (2008). Indecision and Avoidant Procrastination: The Role of Morningness-Eveningness and Time Perspective in Chronic Delay Lifestyles. The Journal of General Psychology, 135, 228-240. https://doi.org/10.3200/GENP.135.3.228-240

[7] Hussain, I. and Sultan, S. (2010) Analysis of Procrastination among University Students. Procedia-Social and Behavioral Sciences, 5, 1897-1904. https://doi.org/10.1016/j.sbspro.2010.07.385

[8] Sirois, F. and Pychyl, T. (2002) Academic Procrastination: Costs to Health and Well Being. Presentation at American Psychological Association Annual Convention, Chicago, 22-25 August 2002.

[9] Hoover, E. (2005) The Chronicle Of Higher Education. Ohio State University.

[10] Goode, C. (2008) Effects of Academic Procrastination: Students Procrastination Affects More Than Grades.

[11] McCloskey, J. (2012) Finally, My Thesis on Academic Procrastination.

[12] Else-Quest, N.M., Hyde, J.S., Goldsmith, H.H. and Van Hulle, C.A. (2006) Gender Differences in Temperament: A Meta-Analysis. Psychological Bulletin, 132, 33-72. https://doi.org/10.1037/0033-2909.132.1.33

[13] Svartdal, F., Pfuhl, G., Nordby, K., Foschi, G., Klingsieck, K.B., Rozental, A. and Rębkowska, K. (2016) On the Measurement of Procrastination: Comparing Two Scales in Six European Countries. Frontiers in Psychology, 7. https://doi.org/10.3389/fpsyg.2016.01307

[14] Steel, P. and Ferrari, J. (2013) Sex, Education and Procrastination: An Epidemiological Study of Procrastinators' Characteristics from a Global Sample. European Journal of Personality, 27, 51-58. https://doi.org/10.1002/per.1851

[15] Masur, P.K., Reinecke, L., Ziegele, M. and Quiring, O. (2014) The Interplay of Intrinsic Need Satisfaction and Facebook Specific Motives in Explaining Addictive Behavior on Facebook. Computers in Human Behavior, 39, 376e386.

[16] Xu, S., Wang, Z. and David, P. (2016) Media Multitasking and Well-Being of University Students. Computers in Human Behavior, 55, $242 \mathrm{e} 250$.

[17] Meier, A., Reinecke, L. and Meltzer, C. E. (2017) Corrigendum to "Facebocrastination"? Predictors of Using Facebook for Procrastination and Its Effects on Students' Well-Being. Computers in Human Behavior, 64, 65-76. https://doi.org/10.1016/j.chb.2016.06.011

[18] Lay, C. and Silverman, S. (1996) Trait Procrastination, Anxiety, and Dilatory Behavior. Personality and Individual Differences, 21, 61-67. https://doi.org/10.1016/0191-8869(96)00038-4

[19] Tice, D.M. and Baumeister, R.F. (1997) Longitudinal Study of Procrastination, Performance, Stress, and Health: The Costs and Benefits of Dawdling. Psychological Science, 8, 454-458. https://doi.org/10.1111/j.1467-9280.1997.tb00460.x 